\title{
Implication of AG -type olivine fabric in garnet peridotite from Yinggelisayi of South Altyn Tagh, NW China
}

\author{
GUO-JIAN GENG ${ }^{1}$, LIANG LIU ${ }^{2}$, MA TUO ${ }^{3}$
}

${ }^{1}$ Department of Geology, Northwest University, Xi'an, China; email:gengsan7710@163.com

${ }^{2}$ Department of Geology, Northwest University, Xi'an, China; email:liuliang@nwu.edu.cn

${ }^{3}$ Department of Geology, Northwest University, Xi'an, China; email:matuo@stumail.nwu.edu.cn

Yinggelisayi garnet peridotite which is located in ultrahigh pressure (UHP) metamorphic belt of South Altyn Tagh, NW China, has experienced the geological process of magma emplacement, continental crust subduction, retrogression and metamorphism in exhumation. In this paper, the olivine in garnet peridotite was analysed in Electron Back Scattered Diffraction(EBSD), and the experimental results show AGtype fabric of olivine, which is characterized as (010) plane strongly aligned subparallel to the foliation and both [100] axis and [001] axis aligned subparallel to the foliation. The type-AG fabric was also called type A+type B fabric, because it belongs to a combination of type A and type B fabric. Olivine of garnet peridotite in Yinggelisayi can be divided into two categories with different particle sizes. Some coarse olivines are surrounded by fine grains, suggesting that the growth of olivine in two stages. In this study, the fabric of olivine with different grain size was further analysed, the results show the coarse grain olivine presented as (010) plane subparallel to the foliation, [001] axis also subparallel to the foliation (type-B, (010)[001]), which corresponds to the UHP environment experienced by garnet peridotite. And the surrounding recrystallized fine olivine is shown as (010) plane subparallel to the foliation, [100] axis of olivine also subparallel to the foliation (type-A, (010)[100]), which is thought to be low pressure and high temperature environment corresponds to the retrogression and metamorphism in exhumation period. In a word, it can be seen that the AG-type fabric of olivine is probably not an independent fabric type, but the result of olivine undergoing different phases. At the same time, it also shows that the study of olivine fabric can also identify the geological process and provide an effective method for the identification of geological periods. 